Revista de Estudios Histórico-Jurídicos [Sección historia del pensamiento político] XXXVIII (Valparaíso, Chile, 2016)

[pp. 395 - 419]

\title{
La UNIÓN Y El PARTido Conservador de VAlParaíso: ¿UNA POSICIÓN DIVERGENTE EN EL CONSERVANTISMO EN MEDIO DE LA CRISIS INSTITUCIONAL DE 1925?
}

[La Unión (The Union) and the Conservative Party of Valparaíso: a divergent position in the conservatism in the middle of the institutional crisis of 1925?]

\author{
Enrique Brahm García* \\ Universidad de los Andes, Santiago, Chile
}

\begin{abstract}
RESUMEN
El tradicional Partido Conservador chileno vería resquebrajada su monolítica unidad en medio de la crisis institucional que empezó a vivir el país como consecuencia de la intervención militar de 1924. Manifestación evidente de esas tensiones internas lo serían la posición que adoptaron los conservadores de Valparaíso que tenían como medio de expresión el diario La Unión, crítica de la dirigencia santiaguina. A través de sus columnas abogarían por la democratización del partido -dar mayor representación a las provincias, a los sectores medios y populares y a la juventud-, se pondrían a la cabeza de quienes querían que
\end{abstract}

\begin{abstract}
The traditional Chilean Conservative Party would fissured its monolithic unity in the middle of the institutional crisis that started to live the country as a consequence of the military intervention of 1924. Clear manifestation of that internal tensions would be the position adopted by the conservatives of Valparaíso, which had as a mean of expression La Unión newspaper, which was critic of Santiago's leadership. By its opinion's sections they would plead for the democratization of the party - to give more representation to the provinces, to the middle and popular classes, and to the Catholic Social Teaching- and those who
\end{abstract}

RECibido el 31 de mayo y ACEPTADO el 30 de junio de 2016

* Profesor de la Facultad de Derecho y del Instituto de Historia de la Universidad de los Andes, Santiago, Chile, Doctor en Derecho por la Universidad de Frankfurt/M. Correo electrónico ebrahm@uandes.cl. Dirección postal Universidad de los Andes, Facultad de Derecho, Av. Monseñor Alvaro del Portillo 12.455, Las Condes, Santiago. Este artículo se enmarca en el proyecto Fondecyt regular ${ }^{\circ} 1151403$. 
los conservadores hicieran suyos los postulados de la doctrina social de la Iglesia y se movieran algo hacia la izquierda y hasta se identificarían con posturas corporativistas y llegarían a mostrar admiración por algunos de los autoritarismos europeos de la época.

Palabras clave

Partido Conservador - Democratización - Social cristianismo - Gremialismo. would move a bit to the left, and even they would identified whit corporatist positions and they would come to show admiration for some European authoritarianisms of that time.

\section{KEYWORDS}

Conservative Party - Democratization - Social Christianity - Gremialismo.

\section{INTRODUCCIÓN}

De entre los partidos políticos tradicionales de Chile pareciera que el más sólido y unido - todavía a comienzos del siglo XX-, gracias a su impronta católica, habría sido el Partido Conservador. "El 'espíritu de ghetto', afirmaría Gonzalo Vial, mantenía incólume su unidad”. Durante el gobierno de Arturo Alessandri los conservadores constituyeron el pilar de la oposición. Con ello, al decir del mismo autor, "las diferencias liberal-conservadoras se minimizaron; les fue antepuesta la defensa del establishment y del grupo social que lo usufructuaba. Nació así la derecha" ${ }^{\text {. }}$

De ahí que la tendencia dominante en la historiografía coincida en afirmar que recién a comienzos de la década de los treinta -fase final del gobierno de Carlos Ibáñez y su caída ${ }^{2}$, seguida de la República Socialista- la unidad del partido se habría empezado a resquebrajar hasta dar forma a la Falange ${ }^{3}$. Son los años en que nace una nueva generación de la juventud católica, que es la que ha concitado el mayor interés entre los historiadores. Entre ellos habría intelectuales de alto vuelo como Mario Góngora ${ }^{4}$, Jaime Eyzaguirre y Julio Philippi $^{6}$, pero también

1 VIAL, Gonzalo, Historia de Chile (1891-1973) (Santiago, Editorial Santillana, 1986), III: Arturo Alessandri y los golpes militares (1920-1925), p. 82.

${ }^{2}$ Brahm García, Enrique, La visión de la diplomacia alemana sobre un momento de crisis del régimen de gobierno chileno: la caída del Presidente Carlos Ibáñez del Campo en julio de 1931, en Revista de Estudios Histórico-Jurídicos 33 (Valparaíso, 2011).

${ }^{3}$ Covarrubias, María Teresa, 1938, la rebelión de los jóvenes (Santiago, Editorial Aconcagua, 1987); Díaz Nieva, José, Chile: de la Falange Nacional a la Democracia Cristiana (Madrid, Universidad Nacional de Educación a Distancia, 2000); GonZÁlez Errázuriz, Francisco Javier, Partido demócrata cristiano. La lucha por definirse (Santiago, Instituto de Estudios Generales, 1989).

${ }^{4}$ Arancibia, Patricia, Mario Góngora: en busca de símismo 1915-1946(Santiago, Fundación Mario Góngora, 1995).

${ }^{5}$ HanISCH, Walter, Jaime Eyzaguirre: historia y pensamiento (Santiago, Universitaria, 1995); GóngorA, Álvaro y otros, Jaime Eyzaguirre en su tiempo (Santiago, Universidad FinisTerrae, 2002).

${ }^{6}$ Millar, René, Pasión de servicio. Julio Philippi Izquierdo (Santiago, Ediciones Universidad Católica de Chile, 2005). 
otros que tendrían una activa vida política en las filas de la Falange y entre los que destacarían Eduardo Frei ${ }^{7}$, Radomiro Tomic y Bernardo Leighton; o dentro del mismo Partido Conservador, como Pedro Lira ${ }^{8}$ y Eduardo Cruz Coke?

Ello explica que obras clásicas sobre el conservantismo, como la de Teresa Pereira, tomen como punto de partida la década de los treinta ${ }^{10}$.

Sofía Correa, por su parte, sostiene que "sólo al comenzar la década de 1930, cuando la intervención de los militares había arremetido en medio del conflicto político, y cuando las corrientes socialistas adquirieron relevancia, la elite tradicional fue desafiada en su manejo indisputado del poder”, y luego agregaba, en referencia a la gran depresión de 1929, que "los partidos históricos, es decir aquellos nacidos en el siglo XIX, debían ahora dar respuesta a los nuevos problemas que hacían sentir su peso en el mundo político; y esta respuesta debía ser a la vez que novedosa, consecuente con su pasado partidista. En el intento surgieron discrepancias internas y divisiones" 11 .

Coincide también con el diagnóstico de que las fisuras dentro del Partido Conservador sólo habrían empezado a tomar forma durante el gobierno de Ibáñez, Claudio Orrego, quién sostiene que recién a partir de ese momento "aparecen los primeros resquebrajamientos en el viejo tronco conservador. Mientras unos buscan acomodarse con la nueva situación y aceptan gustosos su participación en el "Congreso Termal", otros encabezan la defensa de los fueros del derecho violado y de la libertad amordazada" 12 .

Más drásticos todavía en sus juicios sobre los sectores reformistas dentro del Partido Conservador son Gabriel Salazar y Julio Pinto, al sostener que "entre las tendencias emanadas del período revolucionario 1924-1932 y el pasado pre-revolucionario, este partido optó por el último. Que entre la acción católica orientada a construir en directo el orden social cristiano, y la acción política de cuño parlamentario, optó por la última. Que, entre dar vía libre al empresariado industrial capitalista para que este realizara en Chile una revolución industrial basada en el mercado, y cerrar el paso a ese empresariado para dar a la vieja clase política el control directo del Estado Empresarial", los conservadores habrían optado por la última alternativa ${ }^{13}$.

Sin ninguna pretensión de exhaustividad, parece darse una cierta coincidencia en la historiografía en el sentido de que todavía a mediados de la década de los

\footnotetext{
${ }^{7}$ Gazmuri, Cristián, Eduardo Frei Montalva y su época (Santiago, Aguilar, 2000).

${ }^{8}$ Sánchez de Irarrázaval, Elena, Pedro Lira Urquieta: 1900-1981 (Santiago, P. Universidad Católica de Chile, 1989).

${ }^{9}$ Neghme, Amador, Prof. Dr. Eduardo Cruz-Coke Lassaba 1899-1974 (Santiago, Instituto de Chile, Academia de Medicina, 1986).

${ }^{10}$ Pereira, Teresa, El Partido Conservador 1930-1965. Ideas, Figuras y Actitudes (Santiago, Fundación Mario Góngora, 1994).

${ }^{11}$ Correa, Sofía, Con las riendas del poder: la derecha chilena en el siglo XX, (Santiago, Sudamericana.2004), p. 40.

12 Orrego, Claudio, Horacio Walker y su tiempo, (Santiago, Ediciones Aconcagua, 1976), p.14.

13 Salazar, Gabriel y Pinto, Julio, Historia contemporánea de Chile (Santiago, LOM, 1999), I, p. 230.
} 
veinte los conservadores seguirían fuertemente cohesionados, pese al clima revolucionario en el que se vivía. René Millar, por ejemplo, concluye que "de todos los partidos, parece ser el conservador el menos afectado por las divisiones internas. A través de la prensa, del Congreso y de sus convenciones no se aprecian fisuras o pugnas entre dos tendencias" 14 .

Sin perjuicio de ello, es posible encontrar también referencias al proceso de cambios que se estaba iniciando en Chile a partir de la elección de Arturo Alessandri y de los efectos que ellos habrían tenido en el seno del catolicismo chileno y del Partido Conservador. Mario Góngora, por ejemplo, señala que "en el campo católico, estos años son importantísimos"15. Por su parte Gonzalo Vial destaca los cambios que se empiezan a dar en la juventud conservadora en esa época, concretados sobre todo en el seno de la Asociación Nacional de Estudiantes Católicos (ANEC). En su opinión, "el alessandrismo llevaría su oleaje de reforma social [...] hasta el seno del entonces monolítico Partido Conservador" ${ }^{\text {" }}$. Ello sería particularmente evidente en los sectores medios, uno de cuyos representantes más destacados sería Emilio Tizzoni, quién resultaría elegido diputado del partido en 1922, y al que la prensa calificaba cómo "líder de la democracia cristiana" ${ }^{17}$. Vial ya hacía referencia a la existencia de una "semidivisión del Partido entre antiguos conservadores y socialcristianos", que tendría un cierto fondo mediocrático, sin perjuicio de que también hubiera "destacados conservadores socialcristianos de origen aristocrático" ${ }^{18}$.

José Díaz Nieva, por su parte, luego de destacar como ya en la Convención del Partido Conservador de 1901 se proclamaba el deseo de establecer un "Orden Social-Cristiano", señalaba que habría sido en la de 1913 cuándo "el representante de la delegación de Valparaíso, Enrique Delpiano, formulara la primera definición de lo que debía entenderse por "Orden Social-Cristiano". Más todavía, en medio de la discusión Francisco Rivas Vicuña afirmaría que el orden social debía fundarse en la "doctrina de Cristo que, aplicada a las relaciones humanas, se llama Democracia Cristiana, y cuyos principios son los únicos eficaces para llevarnos hacia el progreso"19. El mismo autor destaca que unos años después, en 1920, tomó forma el "Partido Popular", "primera tentativa de los católicos sociales de crear una organización propia, fuera de la disciplina del Partido Conservador". Su impulsor habría sido Bartolomé Palacios, "diputado conservador por Valparaíso entre 1915-1918, regidor por Viña del Mar, y autor de numerosos ensayos sobre diferentes aspectos de la política y la economía, contemplados desde el orden

${ }^{14}$ Millar, René, La elección presidencial de 1920 (Santiago, Editorial Universitaria, 1981), p. 88 .

15 Góngora, Mario, Ensayo histórico sobre la noción de Estado en Chile en los siglos XIX y XX, (Santiago, Ediciones La Ciudad, 1981), p. 109.

16 Vial, Gonzalo, cit. (n. 1), p. 123.

17 Ibíd., p. 158.

18 Ibíd., p. 160.

19 Díaz Nieva, José, cit. (n. 3), p. 29. Cita tomada del libro de Rivas Vicuña, Francisco, La Democracia Cristiana (Santiago, Imprenta de Chile, 1915), p. 47. 
social-cristiano", quién defendía propuestas corporativas, el voto familiar y atacaba con dureza al liberalismo ${ }^{20}$.

En nuestra opinión, durante los movidos meses marcados por la crisis institucional que empezó a vivir Chile con la intervención militar de 1924, y con particular fuerza a partir de la vuelta del Presidente Arturo Alessandri al poder ${ }^{21}$, quién, apoyado por el ejército, pondría en marcha un proceso constituyente para introducir en Chile el régimen presidencial, el Partido Conservador sufriría grandes convulsiones internas que ya preanunciaban su futura división. Frente a la tradicional dirigencia partidaria santiaguina de cuño aristocrático, se empezarían a hacer oír con cada vez mayor fuerza opiniones divergentes emanadas de conservadores de sectores medios y populares, de la juventud y también de las provincias. En este sentido resulta particularmente interesante el papel jugado por el Partido Conservador de Valparaíso, que ya había roto relaciones con la directiva santiaguina en 1923 para restablecerlas recién en febrero de 1925, con la promesa de que el partido adoptaría formas más democráticas. Ellas se concretarían en la Convención General del partido que tuvo lugar en el mismo Valparaíso en el mes de junio de 1925, cuando entraba a su fase final la discusión constitucional.

El pensamiento de los conservadores porteños se expresaría, en lo fundamental, a través del diario La Unión, medio que junto al Diario Ilustrado de Santiago, eran los más importantes periódicos del conservantismo chileno. Durante esos meses se defenderían con fuerza en La Unión ideas social-cristianas y demócrata cristianas, incluyendo proyectos de ese tipo que se practicaban en Europa, pero también aquellas propias del tradicionalismo cristiano y hasta el accionar de algunos gobernantes autoritarios que habían llegado al poder en ese continente y que reaccionaban contra el liberalismo parlamentario dominante hasta ese momento. De esta forma ya en la década de los veinte se veía puesta a prueba la unidad del partido Conservador. Estas son las cuestiones que se tratará de demostrar en este artículo.

\section{LA GRAN CONVENCIÓN DE 1925: LA FUERZA DE LAS TENDENCIAS DEMOCRATIZadoras DENTRO DEL Partido \\ CONSERVADOR}

Reunida la Asamblea Conservadora de Valparaíso el 24 de mayo de 1925, su Presidente, Aníbal Moya, recordaba que durante un par de años había habido un d i v o r c i o con las autoridades centrales del partido, motivado en las aspiraciones democráticas de los conservadores porteños. "Deseo que se sepa, agregaba luego, que la solución de nuestro divorcio con Santiago ha sido hecha a base de llevar a la práctica nuestros anhelos democráticos"22. En efecto, no sólo se había acordado que la próxima convención del partido, que debía tener lugar el mismo

${ }^{20}$ Díaz Nieva, José, cit. (n. 3), p. 38.

${ }^{21}$ Vial, Gonzalo, cit. (n. 1); AHUMADA, Arturo, El Ejército y la revolución del 5 de septiembre de 1924 (Santiago, Imprenta La Tracción, 1931) y Monreal, Enrique, Historia completa y documentada del periodo revolucionario: 1924-1925 (Santiago, Imp. Nacional, 1929).

${ }^{22}$ La Unión (25 mayo 1925), p. 1. 
año 1925, se realizaría en Valparaíso, sino que desde el mismo puerto, desde otros directorios provinciales y diversas organizaciones conservadoras de base, se venía insistiendo desde el mes de marzo, en la necesidad que había de ampliar las bases que estarían representadas en esa gran reunión partidaria; debía lucharse por la "franca democratización del Partido" ${ }^{23}$; que era necesario abrir "de par en par las puertas de la convención a todos los conservadores del país”24.

La democratización de la convención se consideraba como el primer paso para alcanzar un objetivo más de fondo cual era la transformación de los organismos centrales de gobierno del partido, los que se estimaba estaban monopolizados por un pequeño grupo de dirigentes santiaguinos. Fundamentalmente se aspiraba a "modificar la composición del Directorio General en el sentido de que no formen parte de él las fuerzas muertas como ser los ex parlamentarios, ex ministros de Estado, ex diplomáticos, ex consejeros de Estado; que la Convención elija sólo un número reducido. Los demás miembros deben ser los delegados de las Asambleas Departamentales" 25 . Estaba claro que lo que se quería era descentralizar el partido, poniendo el peso en las asambleas de departamento, en desmedro de los tradicionales dirigentes de Santiago.

A ello se agregaba la exigencia de que se abordara con fuerza la así llamada c u e s t i ó n s o c i a l. No en vano, se recordaba en un editorial de La Unión, "es gloria del partido haber adherido desde la aparición de la Encíclica del Papa León XIII en 1891 a las ideas matrices de la democracia cristiana, por cuya difusión ha hecho sin duda más que otro partido alguno"26. Al respecto se publicarían una serie de comunicaciones de los distintos obispos chilenos, en una de las cuales se recordaba al gran rival de Bismarck ${ }^{27}$ en el parlamento alemán de fines del siglo XIX, el pequeño gran líder del partido católico (Zentrum) Ludwig Windthorst ${ }^{28}$, quién habría señalado que "la única manera de combatir el socialismo es realizando todo cuanto hay en él de razonable"29.

Finalmente en las bases para la convención que debía tener lugar en el mes de junio, aprobadas por el Directorio General Conservador, se establecía que "La Convención será formada únicamente", "por los delegados departamentales designados en conformidad a las estipulaciones contenidas en estas bases"; "por los parlamentarios del período de 1924 y los candidatos que llegaron a las urnas el 2 de marzo de ese año"; "por los profesores universitarios"; "por los clubes y centros de propaganda conservadores" ${ }^{30}$. De esta forma, ya en la generación misma de la convención, se daba un avance democratizador, en el sentido de que

${ }^{23}$ La Unión (18 mayo1925), p. 8. Cfr. La Unión (2 abril 1925) p. 6.

${ }^{24}$ La Unión (27 marzo 1925), p. 8.

${ }^{25}$ La Unión (15 abril 1925), p. 9.

${ }^{26}$ La Unión (15 junio 1925), p. 3. Cfr. FogarTy, Michael P., Historia e ideología de la Democracia Cristiana (Madrid, Editorial Tecnos S.A., 1964).

${ }^{27}$ GALL, Lothar, Bismarck.Der weisseRevolutionär (Frankfurt/M., Ullstein, 1983).

${ }^{28}$ Morsey, Rudolf, Von Winthorstbis Adenauer (Paderborn, Schöning, 1997).

${ }^{29}$ La Unión (25 marzo 1925), p. 7.

${ }^{30}$ La Unión (5 mayo 1925), p. 9. 
las normas señaladas apuntaban a robustecer la representación de las provincias y de las organizaciones conservadoras de base.

La discusión se trasladaría luego al seno de la Convención misma, la que sesionaría en Valparaíso entre los días 14 y 16 de junio de 1925. En ella los representantes de Valparaíso, insistirían en la necesidad que había de reformar los Estatutos del partido en un sentido similar, abogando porque se reemplazara la exigencia de estar inscrito en los registros electorales para poder participar activamente en la vida partidaria, por la de tener 18 años de edad; reclamando que se diera mayor injerencia a las directivas provinciales en la designación de los candidatos a parlamentarios y, cómo señalaba el delegado provincial de Valparaíso y activo periodista de La Unión, Rafael Urrejola, “eliminar de la dirección del Partido a toda persona que no haya sido directamente elegida por los correligionarios con ese objeto", para "dar cabida en esa dirección a todos los elementos que forman efectivamente el Partido y lo arraigan en la opinión pública" y asegurar la independencia y conveniente autonomía del Partido en provincias" 31.

Una vez terminada la Convención y aprobados los nuevos estatutos del partido, los conservadores de Valparaíso y el diario La Unión celebrarían lo que consideraban un triunfo pleno de sus propuestas. En un artículo del periódico conservador porteño titulado "Democracia y regionalismo", se señalaba que "si Democracia es el gobierno del pueblo por el pueblo, no existe en Chile partido más democrático que el Conservador, después de las reformas trascendentales acordadas por la Convención y que han entregado el rumbo general de las fuerzas, la norma de procedimientos de sus representantes en el Congreso y el programa mínimo de acción que estos deben desarrollar, a las resoluciones del Directorio General, después de disponer que este Directorio sea formado, exclusivamente, de los elegidos y señalados por las Asambleas Departamentales”. Y para ser miembro de esas asambleas a partir de ahora sólo se requería tener 18 años, haber firmado los registros del partido y pagar la cuota partidaria correspondiente ${ }^{32}$.

Poco antes, en otro editorial titulado "El más democrático de los partidos chilenos", se destacaba como la principal de las reformas aprobadas por la Convención, la nueva organización que se daba al Directorio General, autoridad suprema del partido. "Se constituía antes por un grupo enorme de personas, una legión incontable, en que entraban senadores, diputados y Consejeros de Estado; ex senadores, ex diputados y ex Consejeros de Estado; directores honorarios, centenares de delegados y señores señalados por las Convenciones y por todo aquel que pagara quinientos pesos a la Tesorería General, o sea, multitud toda residente en Santiago [...] Era, pues, una masa en que fatalmente debía predominar el espíritu oligárquico, plutocrático y nepótico de la capital, en la cual se estrellaban los esfuerzos de la juventud renovadora, de las gentes modestas y de los que, desvinculados de los dirigentes luchan a lo largo del país por los ideales conservadores". Ahora en cambio se habría consagrado el "predominio incontrarrestable e incontrarrestado de la Asamblea por encima de todos y de todo" 33 .

\footnotetext{
31 La Unión (14 junio 1925), p. 5.

32 La Unión (21 junio 1925), p. 3.

33 La Unión (18 junio 1925), p. 3.
} 
La gran Convención conservadora de 1925 aparece como un evento central en la historia del Partido Conservador o, por lo menos, del que se esperaba mucho. Había sido anunciada con gran anticipación y la prensa conservadora de la época - La Unión de Valparaíso, El Diario Ilustrado- le dedicaría un sinnúmero de artículos a través de los que se expresarían las esperanzas que tenían puestas en ella todos los estamentos del partido y hasta de la Iglesia. Por otra parte sus conclusiones, por lo menos en parte, no dejaban de ser revolucionarias. Sin embargo llama la atención el hecho de que luego fuera rápidamente silenciada y casi desapareciera de la historia partidaria. En efecto, no se la menciona en la "Reseña de las XIV Convenciones Generales del Partido Conservador 1878-1947”, publicada en $1947^{34}$, ni en la obra clásica de Ignacio Arteaga Undurraga ${ }^{35}$. En ambas se pasa de la IX de 1921 a la X de 1929 como si la de 1925 no hubiera tenido lugar. En todo caso, a la rápida, de pasada y sin dar ningún dato específico sobre la misma, se la menciona en la obra de Juan Díaz Salas "Bosquejo histórico del Partido Conservador" publicado en $1935^{36}$. Más modernamente, llevados por ese impulso, casi no hacen referencia a ella Cristián Garay en su tesis doctoral inédita "El Partido Conservador chileno 1857-1966. Tendencias internas y conflictos doctrinarios" 37 , ni José Díaz Nieva en su "Chile: de la Falange Nacional a la Democracia Cristiana" 38 .

Resulta evidente que los tradicionales sectores dirigentes del partido no quedaron conforme con parte por lo menos de los acuerdos alcanzados en la Convención de 1925. Prueba evidente de lo anterior es el hecho de que en la Convención siguiente, la de 1929, que sería presidida por el mismo Presidente del Partido que lo era en 1925, Arturo Lyon Peña, se derogarían importantes normas contenidas en los Estatutos partidarios, y que tanto habían celebrado en su momento los conservadores de Valparaíso. Ello se haría evidente por lo menos en dos aspectos cruciales. Por una parte, en la forma de integración del Directorio General del Partido, del que volverían a formar parte los ex Senadores, Diputados y Ministros de Estado y los mayores contribuyentes del Partido, "entendiéndose por tales, los correligionarios que paguen a la Tesorería General una cuota anual mínima de $\$ 500$ " (Art. 20, 6). Además, formarían también parte de ese ente directivo, más de 50 directores nombrados por la misma Convención ${ }^{39}$. Por la otra, los Directorios Departamentales y Provinciales del Partido perderían el papel central que se les había asignado en la Convención anterior en orden a designar los candidatos a Diputado y Senador. De acuerdo a los estatutos aprobados en 1929 los diputados serían elegidos ahora por la Asamblea Departamental de una lista elaborada por

${ }^{34}$ Reseña de las XIV Convenciones Generales del Partido Conservador 1878-1947 (Santiago, Imprenta Chile, 1947).

35 Arteaga Undurraga, Ignacio (Comp.), Partido Conservador. XIV Convención Nacional 1947. Notas históricas, 1823-1947 (Santiago, 1947).

${ }^{36}$ Díaz Salas, Juan, Bosquejo histórico del Partido Conservador (Santiago, 1935), p. 80.

37 Garay, Cristián, El Partido Conservador chileno 1857-1966 (Madrid, Tesis doctoral UNED, 2005).

${ }^{38}$ Díaz Nieva, José, cit. (n. 3).

${ }^{39}$ Memoria de la Convención General del Partido Conservador del año 1929 (Santiago, 1930), p. 87. 
la Junta Ejecutiva y esta designaría directamente a los candidatos a Senador ${ }^{40}$. Las Asambleas partidarias perdían buena parte del poder conquistado en 1925 el que volvía a manos de la tradicional dirigencia santiaguina.

\section{TRADicionalismo, GREMIALISMO Y MODELOS} AUTORITARIOS

Una de las diferencias más marcadas que puede encontrarse entre la dirigencia santiaguina del Partido Conservador y los conservadores de Valparaíso, los que expresaban sus ideas a través del diario La Unión, es que mientras los primeros seguían adheridos al tradicional parlamentarismo liberal, característico del Chile decimonónico, parte por lo menos de los conservadores porteños tendían a identificarse con corrientes tradicionalistas y corporativistas. Mientras el partido, cómo es natural, seguía fiel al sistema partidista característico de nuestro sistema político a partir de la llamada "cuestión del sacristán" 41 y que se había ido consolidando en los últimos decenios del siglo anterior y defendía el sistema electoral vigente ${ }^{42}$, en Valparaíso había quienes abogaban por que su lugar lo ocuparan los gremios y se introdujera un nuevo sistema electoral de base gremial familiar.

"Cuántos, devotos al culto de las realidades desearíamos que la voluntad popular no se manifestase por el órgano artificial de los partidos, sino por el órgano natural de las corporaciones orgánicas", se afirmaba en un artículo editorial de La Unión ${ }^{43}$. "Ese advenimiento gremial, se señalaba en otro, se viene realizando en todos los órganos de la vida chilena, reflejo en este caso, de la vida universal. Todo oficio, toda profesión, todo orden de trabajo, agrupa, como por instinto los individuos componentes" y así se puede "defender el derecho de cada uno con la fuerza colectiva de todos" ${ }^{44}$. Y según la doctrina cristiana esa forma de organización debía atravesar a todas las clases sociales. "Hay que ver con amor y confianza ese hervor gremialista de los obreros que se organizan con el 'derecho natural' en la mano, con frase de León XIII ${ }^{45}$, testimonio altísimo e imparcial. Pero son igualmente 'fuerzas vivas', y como tales no renunciantes a su especial manera de concebir y querer las cosas públicas, los adinerados de todo orden; industriales y banqueros, terratenientes y ganaderos, mineros y propietarios" ${ }^{\prime 6}$.

"Fuerzas vivas" era otra expresión que se usaba también de manera constante para enfrentarla a la abstracción de la representación partidista y para resaltar el

${ }^{40}$ Ibíd., arts. 34 a 36, p. 89.

${ }^{41}$ Brahm García, Enrique, Manuel Montt y el quiebre del tronco pelucón en: Bravo Lira, Bernardino y Vicencio Eyzaguirre, Felipe, Manuel Montt. Educador, legislador, gobernante $y$ magistrado en el bicentenario de su nacimiento (1809-2009) (Santiago, Fundación Manuel Montt, 2009), I, pp. 253ss.

${ }^{42}$ Millar, René, cit. (n. 14).

${ }^{43}$ La Unión (1 abril 1925), p. 3.

${ }^{44}$ La Unión (11 abril 1925), p. 3.

${ }^{45}$ El Papa León XIII (1810-1903) gobernó la Iglesia entre 1878 y 1903. Entre otros muchos documentos pontificios promulgó en 1891 la encíclica Rerum Novarum con la que se inició el Magisterio Social Pontificio.

${ }^{46}$ La Unión (30 abril 1925), p. 3. 
valor de la organización gremial. Sería, por lo demás una expresión "netamente cristiana”, usada ya por la organizaciones gremiales medievales, por los filósofos católicos del siglo XIX, consagrada por León XIII y la "usan y repiten mil veces Toniolo $^{47}$, Rutten ${ }^{48}$, Mercier $^{49}$, Olgiati ${ }^{50}$, todos los grandes pensadores católicos" ${ }^{\text {" } 1 . ~}$

La organización gremial, profesional sería, la que más se conforma a la naturaleza del hombre" se afirmaba en La Unión ${ }^{52}$, mientras que el sistema vigente, centrado en los partidos y en el sufragio universal, al que se podría llamar "liberal, individualista, parlamentario, rusoniano", se basaría en "falsedades evidentes". Ellas serían por lo menos cuatro: “a) La nación es un conjunto de individuos, no un organismo complejo con múltiples miembros y células entre el hombre y el Estado" [... "b) La perfecta democracia consiste en que un 5 o $10 \%$ de ciudadanos sean los únicos que elijan los gobiernos, imperando feudalmente sobre el 90\%" [... "c) Quedan excluidos prácticamente de la gobernación la técnica y la clase asalariada" [...] "d) "Para que esa minoría pueda dominar a la mayoría, se crean organizaciones partidarias las cuales tienen derecho al usufructo personal de la burocracia" 53 . Para los católicos que se identificaban con el Partido Conservador, el modelo debía ser el partido católico belga que, de acuerdo a los conceptos desarrollados por el abate Mellaerts ${ }^{54}$ y Georges Helleputte ${ }^{55}$, estaba organizado como una "Federación de cuatro Ligas de Sindicatos: profesionales, campesinos, obreros y empleados" 56 .

Las críticas expresadas desde el órgano conservador de Valparaíso iban dirigidas tanto a los partidos como al sistema electoral que lo hacía posible. Tan es así que hasta se celebraba que tras el fin de la Primera Guerra Mundial se hubieran alejado del "sufragio universal" y de conceptos como la "voluntad popular" o el de "soberanía nacional" y del tradicional parlamentarismo, una serie de países,

${ }^{47}$ Giusseppe Toniolo (1845-1918). Pensador católico que tuvo como inspiradores a Santo Tomás y a Santa Teresa, para quien los sistemas políticos que no se basaban en Dios, como el liberalismo y el socialismo, no podían perdurar. Habría estado entre los colaboradores de León XIII cuando redactó la encíclica Rerum Novarum. Cfr. FogarTy, Michael P., cit. (n. 26), p. 131.

${ }^{48}$ Martin-Hubert Rutten (1841-1927), dominico belga, que llegaría a ser obispo de Lüttich, y también secretario general de los sindicatos cristianos belgas; fue uno de los intelectuales más destacados de la democracia cristiana europea. Cfr. FogARTY, Michael P., cit. (n. 26), p. 467.

${ }^{49}$ Cardenal Désiré Félicien-Francois-Joseph Mercier (1851-1926). Sacerdote belga, fundador del Alto Instituto de Filosofía de la Universidad Católica de Lovaina, se encuentra entre los iniciadores del neotomismo. Cfr. Fogarty, Michael P. (n. 26), p. 647.

${ }^{50}$ Monseñor Francisco Olgiati, profesor de la Universidad Católica de Milán.

51 La Unión (27 abril 1925), p. 3.

52 La Unión (26 mayo 1925), p. 7.

53 La Unión (20 julio 1925), p. 3.

54 Jacob Ferdinand Mellaerts (1845-1925). Sacerdote belga, impulsor del movimiento cooperativo y fundador de la Unión de Agricultores. Cfr. FogarTy, Michael P., cit. (n. 26), pp. 394 y 397.

55 Georges Augustin Helleputte (1852-1925). Profesor universitario y político belga, miembro del Partido Católico, importante figura del movimiento social-cristiano, fundaría ligas de trabajadores que luego se integrarían en una Liga Democrática belga. Cfr. FogarTy, Michael P., cit. (n. 26), p. 316.

56 La Unión (9 abril 1925), p. 3. 
desde la Rusia revolucionaria ${ }^{57}$ a la Italia de Benito Mussolinii ${ }^{58}$. Y hasta en Chile la población habría respirado aliviada cuando en el mes de septiembre de 1924 se disolvió el Congreso Nacional"59. Para el editor de La Unión, "el 'sufragio universal' quiere decir que de cada 100 chilenos, 4 legislan, gobiernan y administran como les da la gana, y 96 pagan y obedecen. Y esta exclusión del 96\% se llama 'voluntad popular' y 'sufragio universal'”. Para llegar a esa cifra se partía de lo que era la población del país en esos años y se iban luego descontando los que no tenían derecho a voto: las mujeres, los menores de 21 años, los extranjeros, los analfabetos, los locos, los militares y los policías. Y si se agregaban los fraudes que se hacían a través del manejo de las inscripciones electorales el porcentaje de los electores se reduciría a sólo un 2,5\% de la población del país ${ }^{60}$. Por eso es que sería una alternativa mucho mejor introducir "el sufragio familiar-gremial, según el cual una Cámara sea elegida a base de representantes gremiales y otra Cámara a base de votos familiares" ${ }^{1}$. Con este sistema, "substituyendo lo vertical -que es lo artificioso- por lo horizontal que es lo natural", la participación política llegaría al $99 \%{ }^{62}$. Concretando lo anterior, en un artículo publicado en La Unión se señalaba que en la cámara gremial "votarían todos los que en Chile trabajan con las manos o con el cerebro: obreros y empleados, curas y doctores, militares y abogados, hombres y mujeres, chicos y grandes". Mientras que en la cámara familiar "votarían todos los chilenos organizados en familias: el padre por sí y por sus hijos menores; la madre por sí y por sus hijas menores; aún, los que forman familia espiritual" 63 .

Por lo demás, cómo en parte ya se ha venido señalando, y cómo era propio de un medio de prensa que representaba al catolicismo, estas doctrinas corporativistas se fundamentaban con la doctrina de la Iglesia. "Deberíamos comenzar a creer más en Santo Tomás que en Montesquieu, señalaba un articulista, a tener más fe en León XIII que en Rousseau; cerrar de una vez las fantasías del individualismo anticristiano, para abrir los libros de la filosofía católica" ${ }^{44}$. Más todavía, entre sus representantes se destacaban particularmente algunos: Balmes ${ }^{65}$, Donoso Cortés ${ }^{66}$, pero, por encima de todos Juan Vásquez de Mella ${ }^{67}$, "gran político español”68,

\footnotetext{
${ }^{57}$ Figes, Orlando, La Revolución Rusa, 1891-1924: la tragedia de un pueblo (Barcelona, Edhasa, 2000).

${ }^{58}$ Gentile, Emilio, Fascismo: historia e interpretación (Madrid, Alianza, 2004); El culto del littorio: la sacralización de la politica en la Italia Fascista (Buenos Aires, Siglo XXI, 2007); El Fascismo y la marcha sobre Roma (Barcelona, Edhasa, 2014).

${ }^{59}$ La Unión (7 mayo 1925), p.3. Cfr. VIAL, Gonzalo, (n. 1), pp. 402ss.

${ }^{60}$ La Unión (7 mayo 1925), p. 3.

${ }^{61}$ La Unión (8 mayo 1925), p. 3.

${ }^{62}$ La Unión (27 abril 1925), p. 3. Cfr. La Unión (1 junio 1925), p. 3.

${ }^{63}$ La Unión (8 mayo 1925), p. 3.

${ }^{64}$ La Unión (27 abril 1925), p. 3.

${ }^{65}$ Jaime Balmes (1810-1848). Sacerdote y filósofo español cuya obra fue muy influyente en la conformación del pensamiento político católico.

${ }^{66}$ Juan Donoso Cortés (1809-1853). Gran exponente del pensamiento tradicional católico español frente a los avances del liberalismo.

${ }^{67}$ Juan Vázquez de Mella (1861-1928). Figura señera del tradicionalismo católico español.

${ }^{68}$ La Unión (17 mayo 1925), p. 7.
} 
"una de las mentes más preclaras de Europa" ${ }^{69}$.Y antes se había hecho referencia al surgimiento en España de la "Escuela Tradicionalista", que había tenido a su cabeza al padre Alvarado el notable "Filósofo Rancio"70, para mencionar luego al Cardenal Izquierdo y al "liberal catalán Capmany"71. Por último, también había referencias en La Unión, con tonos admirativos, a Charles Maurras ${ }^{72}$, el católico y "eminente pensador" de la Acción Francesa"73.

Un aspecto distinto a destacar, aunque también se relaciona con lo que se ha sostenido en los últimos párrafos, es que mientras la dirigencia partidaria conservadora seguía aferrada al tradicional régimen parlamentario que se practicaba en Chile desde fines del siglo XIX, sectores del conservantismo porteño y el diario La Unión tendían a mirar con simpatía algunos modelos autoritarios-que habían terminado en sus países con el parlamentarismo- que se estaban practicando en Europa. Destacan en este sentido las páginas que se dedican a exaltar la figura "magna" de Benito Mussolini ${ }^{74}$, de quien se señala que "goza de gran popularidad"75 y entre sus obras se destacaban la legislación antimasónica ${ }^{76}$ y su postura en favor del voto femenino, que era una bandera de lucha del conservantismo chileno. En este último caso un articulista destacaba que, al jugarse por el voto de la mujer, "la superioridad cualitativa del jefe del fascismo, se ha manifestado una vez más"77.

Pero el entusiasmo de La Unión llegaba al máximo cuando destacaba de Mussolini sus propuestas corporativistas. Con admiración se citaban las "profundas palabras" que habría pronunciado el líder fascista en un discurso ante sus correligionarios: "toda mi vida he sido yo sindicalista. Y es el Sindicalismo lo que ha de matar al Liberalismo". Con estas palabras y el proyecto de nueva constitución en el que estaba trabajando, "Mussolini y el fascismo superan el terreno de las

${ }^{69}$ La Unión (4 julio 1925), p. 7.

70 Fray Francisco Alvarado (1756-1814). Sacerdote dominico cuyo seudónimo era el de "Filósofo Rancio" que combatiría con fuerza el progresismo y las ideas ilustradas y liberales.

${ }^{71}$ La Unión (17 mayo 1925), p. 7. Antonio de Capmany (1742-1813). Historiador, filósofo y político español que enfrentó a los ilustrados españoles Jovellanos y Campomanes defendiendo la pervivencia de los gremios medievales y que combatiría las nuevas ideas que venían de Francia con las viejas tradiciones españolas.

72 Charles Maurras (1868-1952). Político y escritor francés, fundador de la Acción Francesa, quién había perdido tempranamente la fe y defendía un nacionalismo monárquico extremo. Cfr. Nolte, Ernst, El fascismo en su época: action francaise, fascismo, nacionalsocialismo (Madrid, Península, 1967).

${ }^{73}$ La Unión (7 mayo 1925), p. 3, y (20 julio 1925), p. 3.

${ }^{74}$ La Unión (31 junio 1925), p. 3. En La Unión (7 junio 1925), p. 1, se señalaba: "En tales contingencias nació el fascismo, por obra de Benito Mussolini, hombre enérgico, impulsivo, adiestrado por su pasado revolucionario en el ejercicio eventual de las audacias meditadas, joven y, como decían los latinos homo novus en un instante histórico en que los italianos, casi unánimemente, estaban cansados, cansadísimos de los hombres pertenecientes a la oligarquía que desde 1870 han gobernado nuestro país no sin gloria, pero tampoco generosamente".

75 La Unión (5 abril 1925), p. 1.

${ }^{76}$ La Unión (1 julio 1925), p. 3.

77 La Unión (18 mayo 1925), p. 3. 
dictaduras para entrar en el de los grandes ensayistas innovadores, dignos de ser estudiados por cuantos se interesen en la renovación ideal del mundo"78.

Por lo demás también se destacaba su decidido accionar en el ámbito de la política económica, en cuanto pretendería terminar en ese plano con los abusos del liberalismo, aspecto en el que se lo hacía coincidir-también habían para él palabras elogiosas- con el General Primo de Rivera, el gobernante autoritario de España ${ }^{79}$.

A partir de estos antecedentes, quién escribía "La semana internacional" en La Unión se animaba a sacar conclusiones más generales que denotan la nueva mentalidad dominante en algunos sectores del conservantismo chileno en los años de crisis que vivía el país a partir de la intervención militar de 1924. "En el mundo actual, señalaba, hay tres fuerzas poderosísimas, que, además de ser las más sanas, son las que van adueñándose paso a paso de la opinión: la democracia católica, los socialistas y fuerzas dictatoriales de varios países. Pues bien: las tres fuerzas tan distintas en su origen, tan contradictorias en sus bases, de tan diferentes temperamentos, coinciden providencialmente en unos dos puntos capitales: en que las bases sociales y políticas de los tres siglos últimos son inaceptables y en que una sana organización sindicalista de la política y de la economía, es el único remedio al actual estado social" $"$.

En todo caso, a diferencia de la postura que defendía la democratización del partido, cuyo éxito en la Convención de 1925 ya se ha señalado, quienes sostenían posiciones corporativistas, tradicionalistas y hasta simpatizaban con modelos autoritarios extranjeros, y que tenían importante presencia en las páginas de La Unión, estaban en minoría dentro de las filas del Partido, incluso entre los conservadores de Valparaíso. En efecto, ninguna de sus posturas quedaría recogida en las actas de la Convención. A lo más que se llegó en estas materias fue a la presentación de una "indicación" de José Luis Sepúlveda en la que se señalaba: "El P.C. rechaza la constitución individualista de la sociedad y aspira a su constitución orgánica y, por consiguiente propenderá, en lo económico, a la cooperación de patrones y obreros y, en lo político, a la representación corporativa. Para lo primero estimulará en la legislación la participación en los beneficios y la formación de cooperativas de producción; para lo segundo, procurará que su representación parlamentaria esté formada por representantes de las clases o grupos sociales" ${ }^{" 1}$. Esta indicación no resultaría aprobada.

De esta forma en la Convención del año 1925 hubo finalmente acuerdo en la defensa del régimen parlamentario que se aplicaba en el país, e incluso los mismos representantes de Valparaíso se manifestarían contrarios al proceso de reforma constitucional que estaba llevando adelante el Presidente de la República Arturo Alessandri con apoyo de los militares ${ }^{82}$. Tampoco hubo reparos de fondo contra el sistema electoral vigente, sin perjuicio que se quisieran limitar los abusos que

${ }^{8}$ La Unión (6 julio 1925), p. 3.

79 La Unión (2 mayo 1925), p. 3. Cfr. Ben AmI, Shlomo, El cirujano de hierro: la dictadura de Primo de Rivera (1923-1930) (Barcelona, RBA, 2012).

${ }^{80}$ La Unión (6 julio 1925), p. 3.

${ }^{81}$ La Unión (14 junio 1925), p. 1.

${ }^{82}$ La Unión (14 y 15 junio 1925), pp. 1 y 5. 
se cometían a través del mismo. Así por ejemplo, hubo acuerdo en exigir la "independencia del Poder electoral respecto del Ejecutivo", la "inscripción y depuración permanente de los registros" y la "calificación de las elecciones por un tribunal independiente" 83 . También al tenor de lo que estaba ocurriendo en algunos países europeos y que había sido destacado por los editores de La Unión, la Convención reconocía "a la mujer la capacidad para elegir y ser elegida, propiciando desde luego su participación en las elecciones municipales" ${ }^{4}$.

Recién en la Convención de 1929 se notaría un cambio más marcado en estas materias, pero no en el sentido que se había defendido en las páginas de La Unión durante el año 1925. En efecto, como consecuencia de las convulsiones sociales que se vivían en Chile desde la intervención militar de 1924, que tenían como trasfondo una crisis económica que estaba por culminar en la "gran depresión”, y la presión que ejercían sobre los sectores tradicionales que habían dominado la política chilena desde los inicios de la república, los sectores medios y populares, se buscaba tomar resguardos para asegurar la subsistencia del orden social tradicional. Para ello -y debió influir también en la decisión del Partido Conservador el hecho de que se viviera bajo un gobierno autoritario cómo el de Carlos Ibáñez- el régimen parlamentario con el que se identificaban hasta entonces los conservadores debía dar paso a alguna forma de presidencialismo, y el sufragio universal ser reemplazado por fórmulas que aseguraran la debida representación de la elites. En este sentido una campanada de alerta que señalaba el creciente poder electoral de los sectores populares estuvo dado por la elección presidencial de 1925 y la gran votación que obtuvo el candidato derrotado, José Santos Salas, que se enfrentaba a Emiliano Figueroa, a quién apoyaban todos los partidos tradicionales ${ }^{85}$. Según señalaba en su discurso inaugural el Presidente de la Convención del Partido Conservador de 1929, y que lo había sido también de la de 1925, Arturo Lyon Peña, a partir de la Primera Guerra Mundial "el exceso del sufrimiento, lanzó a las masas populares perturbadas, en contra de gobiernos incapaces de defenderse", con lo que se amenazaba, "con mayor o menor violencia, al orden social existente". Para defender el mismo y asegurar el progreso de la República se requería ahora de un ejecutivo fuerte, pero que no fuera "elegido por masas inconscientes", porque con ello se agudizaría el peligro que corría "el país y el orden social". Para asegurar la "representación de la elite", tanto en el ejecutivo como en el legislativo, e impedir que "los elementos sociales más turbulentos" logren "la mayor representación", se proponía modificar "el sufragio universal, introduciendo el voto plural, a base de la familia, propiedad e instrucción” y que la elección del Presidente de la República se hiciera por una "Asamblea Nacional”

${ }^{83}$ La Unión (13 y 15 junio 1925), p. 1.

${ }^{84}$ La Unión (15 junio 1925), p. 1.

${ }^{85}$ Brahm García, Enrique, La elección presidencial de 1925. El candidato equivocado, en San Francisco, Alejandro; Soto, Ángel, Camino a La Moneda. Las elecciones presidenciales en la historia de Chile 1920-2000 (Santiago, Centro de Estudios Bicentenario, 2005). 
en la que también se asegurara la representación de los notables ${ }^{86}$. Todas estas propuestas serían finalmente aprobadas y serían parte del programa del partido ${ }^{87}$.

\section{EN LA AVANZADA SOCIAL}

Es bien sabido que desde la publicación de la encíclica Rerum Novarum por el Papa León XIII en 1891 el Partido Conservador había adherido -con matices- a la doctrina social de la Iglesia y había sido el impulsor de importantes leyes sociales ${ }^{88}$. Ya en la Convención del año 1901 se había concluido que "la suprema aspiración del Partido Conservador es el mantenimiento y desarrollo del Orden Social Cristiano” y este sería definido en la VII Convención por el representante de Valparaíso Enrique Delpiano como "el orden civil en que todas las fuerzas sociales, jurídicas o económicas, cooperan proporcionalmente al bien común; pero que legítimamente y en virtud de la justicia y la caridad tienen un último resultado al bien preponderante de las clases inferiores" ${ }^{\text {". }}$. Esta definición la complementaría en la VIII Convención de 1918 el Vicepresidente del Partido Juan Enrique Concha al señalar que el Orden Social Cristiano "en materia social y política", consiste "en el reconocimiento de los derechos y deberes económicosociales de todas las clases de la sociedad, ricos medianos y pobres, y de un modo especial, protegiendo preferentemente, a la clase media y obrera, porque lo piden y lo necesitan". Y más adelante agregaba: "Si por democracia cristiana se entiende la igualdad de todos, ricos, medianos y pobres, respetándose los derechos de todos ellos conforme a las doctrinas de la Iglesia y a las enseñanzas de la ciencia social, creo interpretar la opinión del conservantismo chileno al decir y proclamar que el partido Conservador chileno es esencialmente-demócrata cristiano" 90 . Por su parte en la IX Convención de 1921 el representante obrero José Luis Sepúlveda -a quién antes se ha citado presentando un voto en favor de soluciones corporativas en la Convención de 1925- propondría "la organización cooperativa del obrero en la producción agrícola e industrial y la retribución directa del salario y participación del obrero en las utilidades" ${ }^{91}$.

En esa línea y en vista de que la "cuestión social", en medio de la crisis institucional y económica que se vivía en el país, había seguido agudizándose, se anunciaba que la Convención del Partido Conservador que debía tener lugar en junio de 1925, tendría en el estudio de los temas sociales uno de sus puntos fuertes. Adhiriendo al manifiesto que enviara a sus bases la dirección del partido, el secretario del obispado de La Serena afirmaría -en un tono que reflejaba muy

${ }^{86}$ Memoria de la Convención General del Partido Conservador del año 1929 (Santiago, 1930), pp. 9ss. Cfr. también ibíd., p. 19ss., discurso de Carlos Estévez.

${ }^{87}$ Ibíd., pp. 74 ss.

${ }^{88}$ Valdivieso, Patricio, Ein WegzurSozialreform in Lateinamerika: Die Rezeption der katholischen Soziallehre Europas in Chile, 1880-1920 (Stuttgart, Verlag Hans-Dieter Heinz, AkademischeVerlag, 1998); VIAL, Gonzalo, cit. (n. 1) I, tomo II, pp. 495ss.

${ }^{89}$ Arteaga Undurraga, Ignacio, cit. (n. 35), pp. 226, 240. Cita según Díaz Nieva, José, cit., (n. 3), pp. 28ss.

${ }^{00}$ Ibíd., pp. 253ss.

${ }^{91}$ Ibíd., p. 264. 
bien el ambiente dominante en las bases conservadoras- que las ideas "políticas, sociales y económicas" allí expresadas "serían las únicas capaces, con la pureza de la Doctrina Cristiana, en el dogma y en las costumbres, de salvar a nuestro pobre y desgraciado Chile, hoy al borde del abismo de una sangrienta revuelta social" ${ }^{\prime 2}$.

Los redactores del diario La Unión y los conservadores de Valparaíso se identificarían de inmediato con ese llamado a enfrentar la "cuestión social"; no en vano se habían puesto a la cabeza de quienes, dentro del partido estaban exigiendo una apertura hacia los sectores medios y populares. Por ejemplo, en el mes de mayo se publicaba en las páginas de La Unión un "notable Memorial” elaborado en el seno de la Universidad popular del Cerro Cordillera y que se había hecho llegar al Presidente Alessandri, donde se señalaba que en medio de la crisis que se vivía en el país "nos encontramos los parias de la sociedad, los modestos empleados públicos y particulares que permanecemos ajenos a toda querella y a los que el desquiciamiento de la República estrangula despiadadamente. Miles y miles de hogares gimen hoy bajo el pesado yugo de la miseria que ha traído como secuela el incremento de la mortalidad infantil, de la delincuencia, de la prostitución, de la indigencia, de la esterilidad voluntaria de las madres, etc., etc." Se citaba luego a santo Tomás de Aquino - "Un mínimo de bienestar es indispensable para vivir honradamente"-, para concluir que "los empleados, al que el actual estado de cosas nos asfixia, tenemos perfecto derecho para provocar un movimiento social formidable que no sólo asegure el derecho a vivir sino que nos haga la vida amable a la vez"93. Mientras que en un artículo editorial, después de señalar que la revolución de enero de 1925 -la de Carlos Ibáñez y Marmaduque Grove contra la Junta de Gobierno- habría tenido cierta popularidad "porque el pueblo creyó que se había dado un golpe de gracia al espíritu aristocrático y oligárquico”, agregaba: "El motor principal de todas estas catástrofes políticas y económicas, es el legítimo deseo de las clases trabajadoras, representadas por una parte pequeña de la oligarquía obrera de las grandes ciudades, de tener una holgada situación económica y un gran influencia y acción política"94.

Respecto al origen de los males que aquejaban a las clases trabajadoras chilenas -sueldos miserables, escasez, miseria endémica, habitaciones insalubres- La Unión y los conservadores coincidían en atribuirlas "a lo que León XIII llamó “el capitalismo inmoral, sin Dios ni conciencia" 95 . Por su parte Pedro Lira Urquieta, Presidente de la Asociación Nacional de Estudiantes Católicos señalaba en un discurso publicado en La Unión que era "una forma de esclavitud la que hace pesar sobre toda una clase social el liberalismo económico predominante en el pasado siglo, y cuya estrepitosa crisis conmueve hoy al mundo entero con el estrépito de su caída, considerando al hombre como una mercadería que se debía explotar" ${ }^{\prime 96}$.

Pero no sólo se criticaba el liberalismo, sino también el actuar demagógico de Arturo Alessandri, que se sintetizaba en la expresión que usaba para dirigirse al

\footnotetext{
92 La Unión (1 abril 1925), p. 9.

93 La Unión (9 mayo 1925), p. 6.

${ }^{4}$ La Unión (9 mayo 1925), p. 6.

${ }^{5}$ La Unión (7 abril 1925), p. 3.

96 La Unión (6 abril 1925), p. 5.
} 
pueblo: "mi querida chusma”. El Presidente de la República habría estimulado "las ilusiones absurdas del proletariado, estímulo que envolvía un mundo de promesas incumplibles"97. Al mismo tiempo los editores de La Unión calificaban al gobierno como populista en la medida en que estaría generando un estancamiento de la economía al haber aumentado los gastos, creado muchos nuevos empleos y establecido - para financiar lo anterior- un exceso de contribuciones. A la larga ello redundaría en un profundo perjuicio para aquellos sectores sociales más postergados a los que se pretendía beneficiar, lo que otra vez provocaría revueltas sociales y podía llevar al país hasta los límites de una revolución ${ }^{98}$.

Ante este panorama la única salida estaba en imponer las soluciones cristianas. "Ni el liberalismo económico sin Dios ni corazón, que engorda a costa del pobre, se señalaba en La Unión, ni el comunismo abominable y sin ley, que tan terribles efectos ha producido en Rusia, pueden ser ideal de progreso y paz. Una vez más el mundo habrá de mirar hacia las soluciones cristianas y organizar la sociedad a la luz de sus armónicas y fecundas doctrinas. Ella evitará la miseria social por un lado, la revolución social por otro lado"99.

Si los conservadores porteños y el diario La Unión se lamentaban de los graves problemas sociales que afectaban a empleados y obreros, como consecuencia de los excesos del capitalismo liberal, mayor temor les embargaba todavía ante la amenaza revolucionaria que se cernía sobre el país como consecuencia de la misma. De esta forma, se criticaba "la propaganda anarquista que viene soliviantando al pueblo contra toda organización social y, ante todo, contra todo poder constituido" ${ }^{100}$. A propósito de algunas protestas y levantamientos obreros que habían tenido lugar en el norte salitrero y de la represión consiguiente practicada por las autoridades de gobierno, se señalaba que los trabajadores habían sido engañados, en cuanto "creían un hecho la implantación del Soviet en Chile y la Dictadura del Proletariado". Sería una constante también el atribuir la agitación revolucionaria a agentes extranjeros: "rusos, peruanos, italianos y españoles" 101 . Los "elementos desquiciadores" estarían constituidos mayoritariamente por "nefastos expatriados extranjeros, que destruyen nuestra paz social y edifican sobre sangre, odios y arenas sus ilusos comunismos"102.

Si La Unión y los conservadores de Valparaíso - y esa cuestión debía estar en el centro de la Convención de 1925- eran partidarios de que el partido Conservador acentuara su carácter social, ello era en parte consecuencia del temor que tenían de que la desmedrada situación en que vivían las clases medias y trabajadoras chilenas pudiera ser el caldo de cultivo para el florecimiento de movimientos revolucionarios de todo tipo que pudieran poner en riesgo la subsistencia misma

97 La Unión (4 junio 1925), p. 3.

98 La Unión (5 mayo 1925), p. 3.

99 La Unión (1 mayo 1925), p. 3.

${ }^{100}$ La Unión (14 junio 1925), p. 1.

101 La Unión (16 junio 1925), p. 3.

${ }^{102}$ La Unión (13 julio 1925), p. 3. Por su parte en La Unión (8 abril 1925), p. 3, se señalaba: "Ha circulado la espeluznante noticia de que se dirigen a estos países de la América del Sur trescientos revolucionarios rusos, enviados por la República de los Soviets, en viaje de propaganda”. 
del orden social. De ahí que debiera rechazarse "la compañía de los descabellados prosélitos de Lenin y volver al concepto democrático del progreso, según el cual la lucha económica se convierte en cooperación activa, en igualdad inicial de oportunidades para abrirse paso y en cooperación de las masas a todos y cada uno de los beneficios de la civilización y de la cultura"103. Para ello el gobierno debía apoyarse en "las clases trabajadoras de orden" lo que garantizaría "una evolución social dentro de las leyes, el orden y el respeto a la propiedad" ${ }^{104}$. No se conseguiría nada sin la cooperación entre el capital y el trabajo, para lo cual La Unión recomendaba el reforzamiento de los sindicatos. Ellos serían -por lo menos los sindicatos católicos-, "un arma social que nada tiene en sí misma de anárquica y que no llega a ser perniciosa sino por el abuso que de ella hacen los extremistas", de ahí que hubieran sido defendidos y recomendados por la Iglesia ${ }^{105}$. Los sindicatos eran la institución fundamental para alcanzar un cierto equilibrio entre el capital y el trabajo, conseguir mejores remuneraciones para los obreros y hacer desaparecer "esas desigualdades irritantes que marcan un abismo entre la opulencia de los menos y la miseria de las multitudes"106.

Desde la perspectiva de La Unión, si los conservadores querían quitar fuerza a las tendencias revolucionarias que amenazaban con desquiciar el orden social, debían alejarse del tradicional liberalismo que había imperado en el partido y hacer realidad la doctrina social de la Iglesia, por ejemplo facilitando el acceso de los obreros a habitaciones sanas y baratas y terminando de paso con los conventillos ${ }^{107}$ y de los campesinos a la propiedad de la tierra, destacándose al respecto el ejemplo mexicano ${ }^{108}$. Pero ello implicaría, al mismo tiempo, un acercamiento político a la izquierda, en defensa del cual periodistas de La Unión destacaban lo que ocurría en algunos países europeos. El caso más conocido es el alemán, donde el sostén de la República que había nacido junto con el fin de la Primera Guerra Mundial era la así llamada "coalición de Weimar", cuyos partidos más fuertes eran el "Zentrum”, católico y los socialistas del SPD ${ }^{109}$. En el país germano "los demócrata-cristianos y los socialistas han gobernado a una y excelentemente", en un período particularmente difícil, lección que se debía "estudiar minuciosamente" ${ }^{\text {"110 }}$.

${ }^{103}$ La Unión (23 junio 1925), p. 8.

104 La Unión (14 junio 1925), p. 3.

105 La Unión (23 marzo 1925), p. 3.

106 La Unión (6 mayo 1925), p. 3. "Se diferencia el sindicalismo del socialismo o comunismo, se señalaba allí, en que estas escuelas pretenden sustituir la tiranía del Estado individualista por la tiranía del Estado colectivista, con el objeto de igualar la condición económica de los hombres; mientras que el sindicalismo, teniendo en vista la naturaleza de las cosas, respeta el derecho de los más capaces y diligentes, sin que esto signifique consentir el abuso".

107 La Unión (15 marzo 1925), p. 13.

${ }^{108}$ La Unión (4 abril 1925), p. 9. Se señalaba que en México el Congreso estaría por aceptar el "fraccionamiento de la tierra y la repartición de ejidos, pero sin violencias". Mientras que "los católicos mexicanos, con el episcopado al frente, exigen que los grandes fundos no cultivados intensamente sean repartidos en parcelas a labriegos aptos".

109 Kolb, Eberhard, Die WeimarerRepublik(München, Oldenburg, 2009).

${ }^{110}$ La Unión (22 junio 1925), p. 3. Mientras que en La Unión (27 abril 1925), p. 3, se destacaba el hecho de que bajo un presidente socialdemócrata -Frederich Ebert- hubieran 
Más interesante de observar le parecía a los editores de La Unión el ejemplo belga ${ }^{111}$. En efecto, de ese país se destacaba el hecho de que en él tomara fuerza la "Escuela social cristiana" que, "al calor de la ciencia de Lovaina y del neoescolasticismo, remozaban los principios cristianos de la política, de la economía y de la sociología" 112 . Por otra parte en el partido católico se esbozaba una división entre el sector más tradicional del partido que se identificaba con principios liberales y sectores de la juventud que adherían de forma más decidida a la doctrina social de la Iglesia. Esta se habría hecho particularmente evidente cuando en medio de una crisis política que se vivía en Bélgica al no poderse conformar una mayoría que diera estabilidad al gobierno "los socialistas declararon que se avenían a gobernar con el partido católico, siempre que el jefe del Gobierno fuese un demócrata cristiano. Los católicos viejos, a regañadientes, aceptaron la solución”. De esta forma se constituyó un gobierno de mayoría católico-socialista, dejando fuera al partido liberal, pero en el fondo también a quienes defendían ideas liberales dentro del partido católico belga ${ }^{113}$. Parecía insinuarse que una división similar dentro del conservantismo se estaba dando en Chile.

Como en su momento se había anunciado, las cuestiones sociales ocuparon un lugar importante en las discusiones de la Convención conservadora de 1925. Ya en su discurso inaugural, Rafael Urrejola, representante de Valparaíso y Presidente de la comisión organizadora destacaba que en Valparaíso habían sido "lanzadas antes que en ninguna otra parte de Chile, como los albores de una vida nueva, las ideas de mejoramiento de la clase media, de renovación social" y donde se había hablado por primera vez "de colocar a la clase media, a los empleados particulares en la situación que merecía” por su aporte al progreso nacional ${ }^{114}$. Por su parte la Convención Provincial de Valparaíso defendía un "régimen tributario a base del impuesto progresivo sobre la renta, con exención de las rentas que la ley califica como necesarias al sostenimiento frugal pero cómodo de una familia de empleados"115. También planteaba una indicación que resultaría aprobada por la Convención que obligaba al Partido Conservador a "luchar por la dictación de una ley que establezca el Accionariado obrero, a partir de cierta utilidad que obtenga el capital" ${ }^{116}$. En el fondo se trataba de introducir en Chile un sistema de participación de los obreros en las utilidades de la empresa. También se aprobaría la proposición del Dr. Ezequiel González Cortés con la que se buscaba impulsar "el bienestar de las clases media e inferior, que constituye la más deseada aspiración del Partido Conservador" y que obligaba al partido a impulsar "la perfecta organización de la institución nacional de los seguros de enfermedad, invalidez

gobernado los cancilleres católicos Wirth y Marx y que el ministro del trabajo dentro de un ministerio socialista hubiera sido durante muchos años un cura católico.

${ }^{111}$ Fogarty, Michael P., cit., (n. 26).

${ }^{112}$ La Unión (22 junio 1925), p. 3.

${ }^{113}$ Ibíd., y La Unión (27 abril 1925),p. 3.

${ }^{114}$ La Unión (13 junio 1925), p. 1.

115 La Unión (14 junio 1925), p. 1.

116 La Unión (13 junio 1925), p. 1. La indicación que resultó finalmente aprobada por la Convención señalaba: "El salario complementario con participación de los beneficios, tomando en cuenta la situación económica de las industrias”. La Unión (14 junio 1925), p. 1. 
prematura o senil"117. Finalmente en el "Programa mínimo" que aprobó la Convención y por cuya ejecución debían luchar los parlamentarios conservadores en el próximo congreso se contemplaban, entre otras medidas, la "Caja agraria (Subdivisión de la propiedad y crédito agrícola)" y la "Edificación de la edificación barata" ${ }^{118}$, cuestión esta última -la de las habitaciones para los obreros-a las que los convencionales habían dedicado bastante espacio en la discusión.

En todo caso la legislación social que se comprometía a impulsar el Partido Conservador, para procurar "un bienestar permanente a las clases necesitadas", se señalaba en una ponencia, no debía llegar al extremo de atacar ni desvalorizar la riqueza nacional ${ }^{119}$. Más explícita en ese sentido resultaba todavía la posición defendida por el Presidente del partido, Arturo Lyon Peña, cuando señalaba que no había que perder de vista, "que la suerte de nuestro obrero debe ser atendida, que debemos hacer grandes sacrificios en su favor, que las leyes sociales necesitan para su aplicación sumas cuantiosas y, por lo tanto, crecidos impuestos. Pero no olvidemos tampoco que nuestro país es un país nuevo que no tiene capitales acumulados, que necesita traer capitales extranjeros, que exigen seguridad y remuneración generosa; que matar la industria es la obra más anti-social y más atentatoria a los intereses del obrero que se pueda acometer" ${ }^{\prime 20}$.

Esta posición más temerosa ante la aprobación de leyes que beneficiaran a los trabajadores sostenida por el Presidente del partido, se acentuaría en la convención de 1929, que presidiría el mismo Arturo Lyon. En efecto, en ella, en muchos de los discursos se insistiría sobre todo en la necesidad que habría de tomar medidas que aseguraran "la subsistencia del orden social" 121 . Esa apertura cuidadosa a las reformas quedaba bien reflejada en la intervención de Alejo Lira Infante cuando sostenía que los principios que inspiraban el programa del partido en lo que a la "cuestión social" se refiere, eran "los del orden social cristiano, del cual resulta, conforme a la feliz expresión de Toniolo, "completa armonía entre los elementos sociales y un mejoramiento de las clases populares"122. Más todavía, ya en lo que se refiere a la introducción de reformas legales concretas, Lira Infante afirmaba que no se había creído necesario "estatuir nada respecto del "derecho al trabajo" -que otras legislaciones contemplan- porque no es el caso de Chile, donde este sobra y donde no se justificaría la fundación de una Caja mediante imposiciones de los patrones, del Estado y de los mismos obreros para acumular fondos con qué subvencionar a estos en caso de desocupación involuntaria”. Para luego agregar que la introducción del contrato de trabajo en la legislación el año 1924 había producido un desequilibrio en favor de los trabajadores, y terminaba refiriéndose a la "vergonzosa holganza de los lunes"123.

Esta nueva posición del partido -frente a lo que se había defendido en la Con-

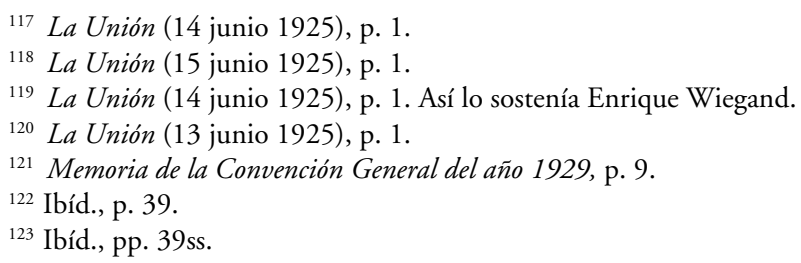


vención de Valparaíso de 1925- en materia de legislación laboral, la expresaba con toda claridad Alejo Lira cuando sostenía que la legislación social que había entrado en vigencia en el país en los últimos años, "había impuesto gabelas y desembolsos considerables a los patrones en beneficio de los empleados y obreros; la balanza de los beneficios que antes se inclinaba a favor del capital, se ha tornado ahora, en muchos casos, favorable al trabajo y en tal forma que se ha roto el equilibrio que debe existir entre ambos factores. No sería recomendable retroceder en el camino recorrido a costa de tantos sacrificios; pero sí lo es el de dar tiempo para arreglar las cargas, a fin de evitar que en la jornada que es larga y es dura, no perezcan algunos, víctimas de exigencias desproporcionadas a sus fuerzas"124.

Todo lo anterior explica el que en el programa aprobado, sin perjuicio de que en él se consideraran una serie de propuestas destinadas a mejorar la legislación social vigente, se señalaba que estas no debían atacar ni desvalorizar la riqueza nacional y la propiedad privada ni exponer "el ahorro y seguridad de las mismas clases necesitadas" 125 .

\section{CONCLUSIÓN}

Las turbulencias que afectaban a Chile desde el momento en que había entrado en crisis el régimen parlamentario, no dejarían incólume al Partido Conservador. A partir de 1920 la historia nacional vivió un acelerado proceso de cambios marcado por la manifestación cada vez más evidente de la cuestión social, la creciente presión que ejercitaban sectores obreros y de clase media por hacer valer sus derechos y expresarse políticamente y por la doble intervención militar de septiembre de 1924 y de enero de 1925 que habían llevado de vuelta al poder a Arturo Alessandri el que, apoyado por los militares, impulsaba la aprobación -sin someterse a los procedimientos establecidos en la Constitución vigente- de un nuevo texto constitucional con el que se impondría un régimen presidencial.

Ese complejo panorama interno, en el que se estaba poniendo en cuestión el orden político y social característico del Chile decimonónico, se vería reforzado por fuerzas profundas que se hacían presentes a nivel internacional y que eran seguidas con particular atención por los conservadores chilenos. En efecto, a partir de la promulgación de la encíclica Rerum Novarum, había tomado forma la doctrina social de la Iglesia y se había desarrollado toda una línea de catolicismo social que en algunos aspectos coincidía con posiciones católicas tradicionalistas y corporativistas, por lo menos en lo que a la crítica al liberalismo se refiere. Más todavía, las turbulencias derivadas de la Guerra Mundial -entre ellas la Revolución Bolchevique- y de los tratados de paz que le pusieron fin, provocaron problemas sociales, económicos y nacionales de envergadura que tendieron a debilitar algunos de los tradicionales regímenes parlamentarios europeos hasta provocar su caída y reemplazo por fórmulas autoritarias y corporativas; mientras que en otros casos

\footnotetext{
${ }^{124}$ Ibíd., p. 45.

${ }^{125}$ Ibíd., p. 78.
} 
se buscaban soluciones por la vía de cimentar alianzas entre los partidos católicos y los socialistas.

Estos cambios influyeron con fuerza en algunos sectores del Partido Conservador, provocando tensiones en su interior. Ello resulta particularmente evidente en el caso de los conservadores de Valparaíso, quienes tenían como medio de expresión el diario La Unión. Como se ha demostrado en este artículo, el conservantismo porteño abogaría con particular insistencia en favor de la democratización del Partido - dar mayor peso en su interior a las provincias, los sectores medios y populares y la juventud-, hasta conseguir su objetivo en la Convención Conservadora que tuvo lugar en su ciudad en junio de 1925. El choque que esto provocaría con la tradicional dirigencia santiaguina sería tan evidente que buena parte de sus logros, que quedaron recogidos en los Estatutos partidarios, serían derogados en la Convención siguiente, la de 1929.

También destacarían los conservadores de Valparaíso y el diario La Unión por sus inquietudes sociales, las que en muchos casos iban más allá que las generales del partido en orden a hacer realidad el orden social cristiano. Se estimaba también que la justicia social de inspiración católica sería el mejor antídoto para frenar los avances del anarquismo y del socialismo revolucionario. Una evidente manifestación de esta apertura hacia la izquierda del conservantismo se encuentra en el juicio positivo que se manifestaba en muchos editoriales de La Unión hacia los gobiernos de coalición católico-socialistas que había en esos años en Alemania y Bélgica.

Menos generalizadas, pero con importante presencia en La Unión, figuraban las posiciones tradicionalistas y corporativistas, radicalmente opuestas a toda forma de liberalismo y al sufragio universal, cómo también la evidente simpatía con que se miraban algunas fórmulas autoritarias europeas, cómo las de Benito Mussolini en Italia y el general Primo de Rivera en España.

Esto no significa que, en lo inmediato -1925-, el Partido Conservador se viera amenazado por una posible división o por la escisión de parte de sus bases, pero si resulta evidente que no se daba una plena cohesión interna y que había muchos importantes dirigentes que no se encontraban cómodos con la línea conservadora dominante, con la tradicional dirigencia santiaguina.

$\mathrm{Al}$ respecto resulta interesante destacar el itinerario que siguieron, a partir del año 1925, algunos de los más representativos dirigentes del conservantismo de Valparaíso, los que además eran periodistas del diario La Unión. Un caso emblemático es el de Fernando Silva Maquieira, el político -fue diputado por Valparaíso entre 1918 y 1921- y empresario conservador que se hizo cargo de $L a$ Unión cuando, al asumir como arzobispo de Santiago, el año 1919, Monseñor Crescente Errázuriz, este decidió que la Iglesia no debía manejar por sí misma empresas periodísticas. Sin perjuicio de su fidelidad al Partido Conservador -de hecho llamó de inmediato a colaborar con él en el diario al senador de ese partido Rafael Urrejola- y de haberse opuesto al golpe militar de enero de 1925, "al extremo de preferir el cierre del diario a la aceptación de la censura, fue, después, 
partidario del gobierno del señor Ibáñez" ${ }^{126}$. Ello se explica porque quería colaborar a la consolidación del régimen constitucional y al éxito del gobierno para bien de los chilenos. "Nació de este modo y por estas circunstancias, se señalaba en un artículo en el que se hacía una historia de La Unión en su cuarenta aniversario, una amistad estrecha entre él y los hombres del Gobierno, amistad que supo guardar lealmente con desinterés acrisolado y hasta el último instante, y que desafió las iras de todos los que conspiraban descubierta u ocultamente y, también, de los que no se conformaron jamás con la presencia de un jefe militar al frente del Estado"127. Ello le ocasionaría serios desencuentros con los dirigentes de su propio partido.

De manera plena se terminaría identificando con el i b a ñ is m o Luis Cruz Almeida, uno de los más representativos periodistas de La Unión, diario del que había sido Director. Dejando atrás su pasado conservador, Cruz Almeida se integraría a la Confederación Republicana de Acción Cívica de Obreros y Empleados de Chile, partido popular, de tendencia corporativista fundado en 1929, que apoyaría al gobierno de Ibáñez ${ }^{128}$.

Más notable es todavía el caso del periodista de La Unión, ensayista y diputado conservador por Valparaíso, Bartolomé Palacios. Joven católico identificado con los contenidos de la encíclica Rerum Novarum, amigo y discípulo del padre Fernando Vives, se encuentra -junto al dirigente sindical Clotario Blest y asesorado por los sacerdotes Guillermo Viviani y Daniel Merino- entre los fundadores del Partido Popular, inspirado en su homónimo italiano. El nuevo partido apuntaba a reunir a los católicos chilenos más identificados con la doctrina social de la Iglesia -los "demócrata cristianos"-, era particularmente crítico con el liberalismo y pretendía reemplazar el sufragio universal por uno de tipo familiar y gremial, pero nunca lograría consolidarse y desaparecería a fines del año $1925^{129}$.

Un último ejemplo de activos periodistas de La Unión y miembros del Partido Conservador todavía el año 1925 y que se decantaron hacia posiciones más de izquierda, puede ser el caso de Guillermo Piedrabuena quien terminaría por ser expulsado del partido por adherir a la candidatura de José Santos Salas, rival de Emiliano Figueroa, candidato apoyado por todos los partidos tradicionales, incluido el Conservador, en las elecciones presidenciales de $1925^{130}$.

De todo lo anterior resulta evidente que en medio de la crisis constitucional que se vivía en 1925, si bien se estaba todavía lejos del surgimiento de la Falange, ya había muchos conservadores que no se sentían cómodos ni con la dirigencia ni con el programa del partido.

126 La Unión (23 enero 1935), pp. 31ss.

127 Ibíd.

${ }^{128}$ biografías.bcn.cl. Consultada (19 mayo 2016). Sobre los orígenes del CRAC, cfr. SCOTT, Harry, Pensando el Chile Nuevo. Las ideas de la Revolución de los tenientes y el primer gobierno de Ibáñez, 1924-1931 (Santiago, Centro de Estudios Bicentenario, 2009), pp. 223ss.

129 Díaz Nieva, José, cit. (n. 3), pp. 37ss.; Vial, Gonzalo, cit. (n. 1), p. 161; Williamson Jordan, L., Don Bartolomé Palacios Silva, en Politica y Espíritu 161 (Santiago, 1956), p. 17; BoIzard, Ricardo, La Democracia Cristiana en Chile. Un mundo que nace entre dos guerras (Santiago, Editorial Orbe, 1963).

${ }^{130}$ VIAL, Gonzalo, Historia de Chile (1891-1973), IV: La dictadura de Ibáñez (1925-1931) (Santiago, Editorial Fundación, 1996), p. 70; BraHm GarCía, Enrique, cit. (n. 85). 


\section{BiBLIOGRAFÍA}

Prensa

Diario La Unión de Valparaíso enero a agosto de 1925 y enero de 1935.

\section{Literatura}

Ahumada, Arturo, El Ejército y la revolución del 5 de septiembre de 1924 (Santiago, Imprenta La Tracción, 1931).

Arancibia, Patricia, Mario Góngora: en busca de si mismo 1915-1946 (Santiago, Fundación Mario Góngora. Universitaria, 1995).

Arteaga Undurraga, Ignacio (Compilador), Partido Conservador. XIV Convención Nacional 1947. Notas históricas, 1823-1947 (Santiago, 1947).

Ben-Ami, Shlomo, El cirujano de hierro: la dictadura de Primo de Rivera (1923-1930) (Barcelona, RBA, 2012).

Boizard, Ricardo, La Democracia Cristiana en Chile. Un mundo que nace entre dos guerras (Santiago, Editorial Orbe, 1963).

Brahm García, Enrique, La elección presidencial de 1925. El candidato equivocado, en San Francisco, Alejandro; Soto, Ángel, Camino a La Moneda. Las elecciones presidenciales en la historia de Chile 1920-2000 (Santiago, Centro de Estudios Bicentenario, 2005.

Brahm García, Enrique, Manuel Montt y el quiebre del tronco pelucón, en Bravo Lira, Bernardino; Vicencio Eyzaguirre, Felipe, Manuel Montt. Educador, legislador, gobernante y magistrado. Estudios en conmemoración del bicentenario de su nacimiento (1809-2009) (Santiago, Fundación Manuel Montt, 2009).

BRAHM GARCía, Enrique, La visión de la diplomacia alemana sobre un momento de crisis del régimen de gobierno chileno: la caída del presidente Carlos Ibáñez del Campo en julio de 1931 en Revista de Estudios Histórico-Jurídicos XXXIII (Valparaíso, 2011).

Correa, Sofía, Con las riendas del poder: la derecha chilena en el siglo XX (Santiago, Sudamericana, 2005).

Covarrubias, María Teresa, 1938, la rebelión de los jóvenes (Santiago, Editorial Aconcagua, 1987).

Díaz Nieva, José, Chile: de la Falange Nacional a la Democracia Cristiana (Madrid, Universidad Nacional de Educación a Distancia, 2000).

Díaz Salas, Juan, Bosquejo histórico del Partido Conservador (Santiago, 1935).

FIGES, Orlando, La Revolución Rusa, 1891-1924: la tragedia de un pueblo (Barcelona, Edhasa, 2000).

FogarTy, Michael P., Historia e ideología de la Democracia Cristiana (Madrid, Editorial Tecnos S.A., 1964).

GaLl, Lothar, Bismarck. Der weisse Revolutionär (Frankfurt/M., Ullstein, 1983).

GaraY, Cristián, El Partido Conservador Chileno 1857-1966. Tendencias internas y conflictos doctrinarios (Madrid, Tesis Doctoral UNED, 2005).

Gazmuri, Cristián, Eduardo Frei Montalva y su época (Santiago, Aguilar, 2000).

Gentile, Emilio, Fascismo: historia e interpretación (Madrid, Alianza, 2004).

Gentile, Emilio, El culto del littorio: la sacralización de la politica en la Italia fascista (Buenos Aires, Siglo XXI, 2007).

GentiLe, Emilio, El Fascismo y la marcha sobre Roma (Barcelona, Edhasa, 2014). 
Góngora, Álvaro y otros, Jaime Eyzaguirre en su tiempo (Santiago, Universidad Finis Terrae, 2002).

GÓNGORA, Mario, Ensayo histórico sobre la noción de Estado en Chile en los siglos XIX y XX (Santiago, Ediciones La Ciudad, 1981).

GonzÁlez ERrázurIz, Francisco Javier, Partido demócrata cristiano. La lucha por definirse (Santiago, Instituto de Estudios Generales, 1989).

Hanisch, Walter, Jaime Eyzaguirre: historia y pensamiento (Santiago, Universitaria, 1995).

Kolb, Eberhard, Die Weimarer Republik (München, Oldenburg, 2009).

Memoria de la Convención General del Partido Conservador del año 1929 (Santiago, 1930).

Millar, René, La elección presidencial de 1920 (Santiago, Editorial Universitaria, 1981).

Millar, René, Pasión de servicio. Julio Philippi Izquierdo (Santiago, Ediciones Universidad Católica de Chile, 2005).

Monreal, Enrique, Historia completa y documentada del periodo revolucionario: 19241925 (Santiago, Imp. Nacional, 1929).

Morsey, Rudolf, Von Windthorst bis Adenauer (Paderborn, Schöning, 1997).

Neghme, Amador, Prof. Dr. Eduardo Cruz-Coke Lassaba (1899-1974) (Santiago, Instituto de Chile, Academia de Medicina, 1986).

NolTe, Ernst, El fascismo en su época: action francaise, fascismo nacionalsocialismo (Madrid, Península, 1967).

Orrego, Claudio, Horacio Walker y su tiempo (Santiago, Ediciones Aconcagua, 1976).

Pereira, Teresa, El Partido Conservador 1930-1965. Ideas, Figuras y Actitudes (Santiago, Fundación Mario Góngora, 1994).

Reseña de las XIV Convenciones Generales del Partido Conservador 1878-1947 (Santiago, Imprenta Chile, 1947).

Rivas Vicuña, Francisco, La Democracia Cristiana (Santiago, Imprenta Chile, 1915).

Salazar, Gabriel y Pinto, Julio, Historia contemporánea de Chile (Santiago, LOM, 1999).

Sánchez de Irarrázaval, Elena, Pedro Lira Urquieta: 1900-1981 (Santiago, P. Universidad Católica de Chile, 1989).

Sсотt, Harry, Pensando el Chile Nuevo. Las ideas de la Revolución de los tenientes y el primer gobierno de Ibáñez, 1924-1931 (Santiago, Centro de Estudios Bicentenario, 2009).

VAldivieso, Patricio, Ein Wegzur Sozialreform in Lateinamerika: Die Rezeption der katholischen Soziallehre Europas in Chile, 1880-1920 (Sttutgart, Verlag Hans-Dieter Heinz. AkademischerVerlag, 1998).

VIAL, Gonzalo, Historia de Chile (1891-1973), I: La sociedad chilena en el cambio de siglo (1891-1920) (Santiago, Editorial Santillana, 1981).

VIAL, Gonzalo, Historia de Chile (1891-1973), III: Arturo Alessandri y los golpes militares (1920-1925) (Santiago, Editorial Santillana, 1986).

VIAL, Gonzalo, Historia de Chile (1891-1973), IV: La dictadura de Ibáñez (1925-1931) (Santiago, Editorial Fundación, 1996).

Williamson Jordan, L., Don Bartolomé Palacios Silva, en Politica y Espiritu, 161 (Santiago, 1956). 
